\title{
Effects of Laser Shock Peening on the Surface Integrity of $18 \%$ Ni Maraging Steel
}

\author{
Luca Petan ${ }^{1}$ - José Luis Ocaña ${ }^{2}$ Janez Grum ${ }^{1}$,* \\ ${ }^{1}$ University of Ljubljana, Faculty of Mechanical Engineering, Slovenia \\ 2 Polytechnic University of Madrid, Laser Center, Spain
}

\begin{abstract}
Maraging steels represent a special group of steels where ultrahigh strength is achieved with precipitation hardening. Because of their superior mechanical properties, maraging steels are used for the manufacturing of parts in the aerospace and tooling industry. Usually these mechanical components operate in demanding environments and conditions where they are subject to mechanical fatigue, thermomechanical fatigue, corrosion, and wear. The scope of the research presented in this paper is to analyze the effects of laser shock peening (LSP) on surface integrity characteristics of X2NiCoMo18-9-5 maraging steel. In this study, maraging steel specimens, in both quenched and aged condition, were treated with LSP by varying the pulse density. The effects of laser treatment on surface integrity were analyzed with roughness, residual stress, and microhardness measurements. According to the measurement results, LSP generated high compressive residual stresses in the steel surface layer with relatively low surface roughness, which indicates possible fatigue resistance improvements in $18 \%$ Ni maraging steel.
\end{abstract}

Keywords: laser shock peening, dislocation, compressive residual stress, microhardness, surface roughness

Highlights

- Maraging steel specimens were treated with LSP.

- Surface integrity of untreated and LSP treated maraging steel specimens was analyzed.

- LSP generated compressive residual stresses in the maraging steel surface layer.

- Strain hardening of the maraging steel surface layer occurred after LSP.

- High compressive residual stresses in combination with relatively low surface roughness can be achieved even without the use of an absorbent coating.

\section{O INTRODUCTION}

Maraging steels represent a special group of ultrahigh strength steels which can be hardened by precipitation of intermetallic compounds at temperatures around $480{ }^{\circ} \mathrm{C}$ [1]. These steels have a high content nickel, cobalt, and molybdenum, while the content of carbon, considered an impurity, is kept as low as possible. Commercially available maraging steels can reach yield strengths up to $2400 \mathrm{MPa}$. In addition to high strength, they are characterized by high resistance to thermal fatigue, high fracture toughness, and good weldability [2]. In order to achieve martensitic transformation during quenching, lower cooling rates are sufficient, and there is less probability for cracking to occur. During age hardening there is very little distortion. Therefore, parts can be machined to final dimensions before the aging process. Maraging steels were primarily developed as high strength structural materials, intended for applications in aeronautical and aerospace. Later on, because of their superior mechanical properties, maraging steels started to be used in the manufacturing of tools [3] such as molds and die-casting dies. Maraging steels are used for the manufacturing of mechanical parts and tools which operate in demanding environments and conditions where they are subject to mechanical fatigue, thermomechanical fatigue, corrosion, and wear. These phenomena have a negative effect on fatigue life and may cause an early failure of the mechanical part.

Fatigue behavior of highly stressed metallic components can be significantly improved by mechanical surface treatments [4] such as shot peening (SP) and laser shock peening (LSP). LSP is an innovative surface treatment [5] that can increase the fatigue strength of metallic parts by generating compressive residual stresses in the thin layer of the treated surface. During LSP, the surface of the treated component is exposed to nanosecond long laser pulses of intense energy from $5 \mathrm{~J}$ to $100 \mathrm{~J}$ [6]. The material in the interaction area with the laser beam vaporizes, and by further absorption of laser energy it ionizes and transforms into plasma. The newly created plasma continues to absorb the laser energy and generates pressure on the surface by transmitting shock waves into the treated material, Fig. 1. When shock wave stresses exceed the yield strength, plastic deformation occurs under the interaction zone between the laser beam and the material. The surrounding material prevents dilatation of the irradiated area of the surface layer, generating compressive residual stresses, which can reach depths up to $1 \mathrm{~mm}$ [7]. LSP treatment is far 
more effective if it is carried out in confined mode, where the metal surface is cowered with absorbent coating and confined by a transparent material like water or glass.

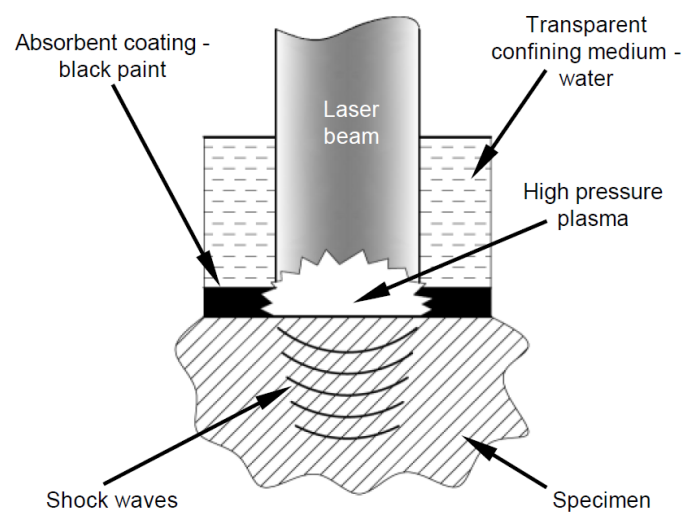

Fig. 1. Schematic representation of the LSP process

Another surface treatment method with the aim of increasing fatigue strength [8] is SP, whose development began in the late 1920s. During SP, the surface of the treated metallic component is exposed to a flux of small particles of high hardness. These particles, also called shot peening medium or simply shots, with a specific size and hardness, usually have a spherical shape and are made out of a metal, ceramic material, or glass. If the kinetic energy of the peening particle exceeds the yield strength threshold of the treated material, plastic deformation under the interaction zone will occur. Each particle, after a highvelocity impact, acts as a small hammer leaving a dent and generating a field of compressive residual stresses [9] and enhancing the hardness of the material [10]. By overlapping the impact zones during SP, or laser beam spots in case of LSP, it is possible to create a relatively uniform layer with compressive residual stresses.

An overview of scientific papers over the last few years shows there is an interest in investigating the possibility of applying surface peening techniques in order to improve the thermal and mechanical fatigue resistance of high-strength steels and tool steels. The first study on the effects of LSP treatment on maraging steel was carried out by Banas et al. [11]. Weldments of $18 \mathrm{Ni}(250)$ maraging steel were exposed to highpower short laser pulses using an Nd:YAG laser. A microstructural study showed an increased dislocation density in the heat-affected zone as a result of lasershock loading. Fatigue test results indicated a $17 \%$ increase in fatigue strength after LSP. Grum et al. [12] and [13] analyzed the effects of LSP on the thin surface

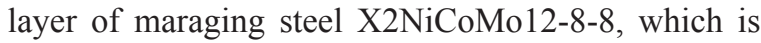

suitable for the production of dies for die casting at temperatures of up to $600{ }^{\circ} \mathrm{C}$. After LSP, compressive residual stresses up to $800 \mathrm{MPa}$ were generated in the surface layer. Lavender et al. [14] carried out a study, whose objective was to investigate the effects of LSP on the life and failure behavior of pilger dies, made of A2 tool steel. After LSP, the life of the pilger dies, which was determined by in-process visual inspection of the tubes being processed, increased by $300 \%$.

Harada et al. [15] examined the influence of shot peening on the surface characteristics of AISI M2, a molybdenum-type high-speed steel. SP with cemented carbide microshots improved surface characteristics as compressive residual stresses up to $2000 \mathrm{MPa}$ were generated near the surface at low surface roughness. The properties of cold work tool steel AISI D2 after SP by FeCrB gas atomized powder were analyzed by Sawada and Yanagitani [16]. Fatigue test results showed the higher fatigue strength of the peened specimens, which was attributed to crack initiation suppression caused by compressive residual stresses generated by the SP process.

Chang et al. [17] conducted various tests to evaluate the effects of shot peening on thermal cracking and mechanical properties of $\mathrm{H} 13$ hot work tool steel. Test results indicate that SP could increase the fatigue strength by two to three times due to the induced compressive stresses.

The main goal of the research presented in this paper is to investigate the effects of LSP treatment on the surface integrity of $\mathrm{X} 2 \mathrm{NiCoMo} 18-9-5$ maraging steel with an emphasis on the residual stress state of the treated surface layer and surface roughness, which can have a significant influence on fatigue resistance. The strain hardening effect of LSP was also analyzed by performing in-depth microhardness measurements.

\section{METHODS AND EXPERIMENTAL DETAILS}

The research presented in this paper was carried out on maraging steel X2NiCoMo18-9-5 / DIN 1.6358, suitable not only as a high strength structural material, but also as a tool steel for molds and die casting tools. The chemical composition and mechanical properties of X2NiCoMo18-9-5 in quenched and artificially aged condition are given in Tables 1 and 2 .

The chosen maraging steel was delivered as a soft annealed rolled plate with $9.5 \mathrm{~mm}$ thickness. In the first stage of our experimental work, square shape specimens measuring $40 \mathrm{~mm} \times 40 \mathrm{~mm}$ were cut out of the maraging plate. The square specimens were then heat treated. The first phase of heat treatment consisted of solution annealing, for $1 \mathrm{~h}$ at a 
Table 1. Chemical composition of X2NiCoMo18-9-5 maraging steel (DIN 1.6358)

\begin{tabular}{ccccccccccc}
\hline $\mathrm{Fe}$ & $\mathrm{C}$ & $\mathrm{C} 0$ & $\mathrm{Ni}$ & $\mathrm{Mo}$ & $\mathrm{Ti}$ & $\mathrm{Al}$ & $\mathrm{Mn}$ & $\mathrm{Si}$ & $\mathrm{P}$ & $\mathrm{S}$ \\
\hline Bal. & $\leq 0.03$ & $8.0-10.0$ & $17.0-19.0$ & $4.5-5.5$ & $0.5-0.8$ & $0.05-0.15$ & $\leq 0.10$ & $\leq 0.10$ & $\leq 0.01$ & $\leq 0.01$ \\
\hline
\end{tabular}

Table 2. Mechanical properties of X2NiCoMo18-9-5 maraging steel (DIN 1.6358)

\begin{tabular}{|c|c|c|c|c|c|}
\hline $\begin{array}{l}\text { Heat treatment } \\
\text { condition }\end{array}$ & $\begin{array}{c}\text { Ultimate tensile } \\
\text { strength } R_{m}[\mathrm{MPa}]\end{array}$ & $\begin{array}{l}\text { Yield strength } \\
R_{p 0.2}[\mathrm{MPa}]\end{array}$ & $\begin{array}{c}\text { Young's modulus } \\
E[\mathrm{GPa}] \\
\end{array}$ & $\begin{array}{c}\text { Density } \\
\rho\left[\mathrm{kg} / \mathrm{m}^{3}\right]\end{array}$ & $\begin{array}{c}\text { Rockwell Hardness } \\
\text { HRC }\end{array}$ \\
\hline QUENCHED & 1070 & 870 & \multirow{2}{*}{195} & \multirow{2}{*}{8100} & 32 to 37 \\
\hline AGED & 2050 & 1900 & & & 52 to 56 \\
\hline
\end{tabular}

temperature of $820^{\circ} \mathrm{C}$, and cooling by air quenching. Afterwards, half of the quenched specimens were exposed to the age hardening process, performed for 3 $\mathrm{h}$ at a temperature of $480^{\circ} \mathrm{C}$. In order to achieve equal initial surface roughness conditions, all specimens were ground and polished. Heat treated and polished specimens were then exposed to laser shock peening in confined mode without an absorbent coating. Water was chosen as a transparent overlay. LSP was carried out using a Q-switched Nd:YAG laser with a wavelength of $1064 \mathrm{~nm}$. The peening treatment was performed using three different laser pulse densities $\left(900 \mathrm{~cm}^{-2}, 1600 \mathrm{~cm}^{-2}, 2500 \mathrm{~cm}^{-2}\right)$, while the laser pulse energy and duration were constant, i.e. $2.8 \mathrm{~J}$ and 10 ns. During LSP, the longitudinal direction of the laser beam path was parallel to the rolling direction, Fig. 2. Specimens with the corresponding designation and LSP processing parameters are listed in Table 3. Effects of the laser treatment on surface integrity were analyzed with roughness, residual stress (RS), and Vickers microhardness (HV) measurements.

\section{RESULTS AND DISCUSSION}

\subsection{Surface Roughness}

Arithmetical mean deviation of the surface profile $R a$ (ISO 4287) [18] and mean roughness depth $R z$ (DIN 4768) [19] were the chosen surface parameters to describe the effects of the LSP treatment on surface roughness of maraging steel. Parameters $R a$ and $R z$ can give complementary information about the surface profile [20]. Roughness measurements were carried out using a Surtronic $3+$ contact profilometer by Taylor Hobson, while the input data was processed with TalyProfile software.

The surface roughness of each specimen was calculated as the average between 5 longitudinal and 5 transversal measurements. The calculated average values with the corresponding standard deviations

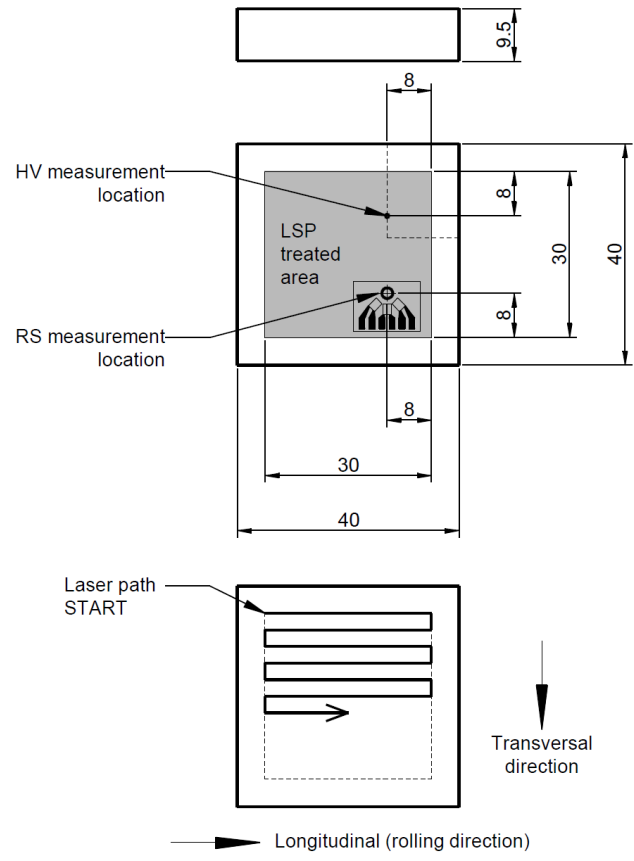

Fig. 2. Specimen dimensions with the LSP treated area

Table 3. Specimens with the corresponding designation and LSP process parameters

\begin{tabular}{ccccc}
\hline $\begin{array}{c}\text { Specimen } \\
\text { designation }\end{array}$ & $\begin{array}{c}\text { Pulse } \\
\text { density } \\
{\left[\mathrm{cm}^{-2}\right]}\end{array}$ & $\begin{array}{c}\text { Laser spot } \\
\text { diameter } \\
{[\mathrm{mm}]}\end{array}$ & $\begin{array}{c}\text { Power } \\
\text { density } \\
{\left[\mathrm{GW} \cdot \mathrm{cm}^{-2}\right]}\end{array}$ & $\begin{array}{c}\text { Overlapping } \\
\text { rate } \\
{[\%]}\end{array}$ \\
\hline Q & - & - & - & - \\
\hline Q-900 & 900 & 1.5 & 15.8 & 78 \\
\hline Q-1600 & 1600 & 1.5 & 15.8 & 83 \\
\hline A-2500 & 2500 & 1.5 & 15.8 & 87 \\
\hline A & - & - & - & - \\
\hline A-900 & 900 & 1.5 & 15.8 & 78 \\
\hline A-1600 & 1600 & 1.5 & 15.8 & 83 \\
\hline A-2500 & 2500 & 1.5 & 15.8 & 87 \\
\hline
\end{tabular}

for parameters $R a$ and $R z$ are represented with column charts in Fig. 3 and Fig. 4, respectively. The initial topographic state, before exposure to the laser treatment, is represented by specimens Q and A. The 
arithmetic mean roughness of un-shocked specimens is around $0.17 \mu \mathrm{m}$. The column charts clearly show a significant increase in surface roughness after LSP was applied. The $R a$ of LSP treated quenched specimens and aged specimens ranges from $0.71 \mu \mathrm{m}$ to $0.93 \mu \mathrm{m}$ and from $0.69 \mu \mathrm{m}$ to $1.11 \mu \mathrm{m}$, respectively. Minimum roughness was achieved on specimens Q-900 and A-900, which were shock peened using 900 $\mathrm{cm}^{-2}$ pulse density. Specimens Q-2500 and A-2500, treated with the highest pulse density, have the highest $R a$ roughness. We can obtain similar findings for $R z$ roughness measurement results by comparing both column charts.

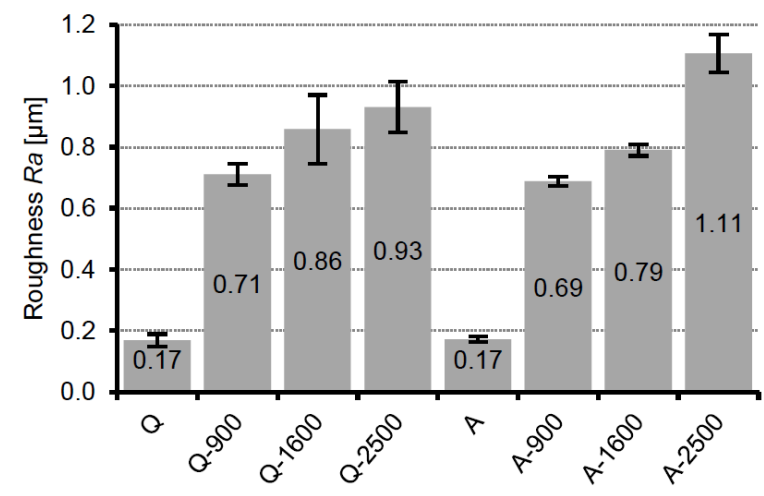

Fig. 3. Roughness $R a$ of untreated and LSP treated maraging steel specimens

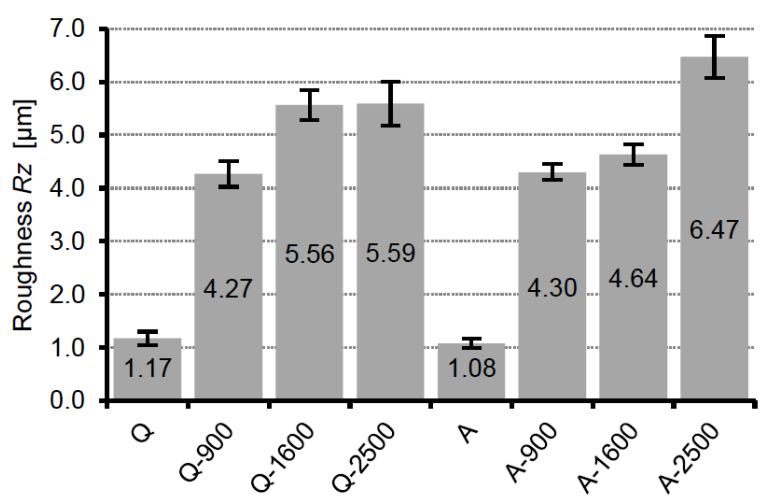

Fig. 4. Roughness $R z$ of untreated and LSP treated maraging steel specimens

Roughness measurements indicate that by increasing the LSP pulse density a surface with a higher $R a$ roughness is generated. The increase in surface roughness is a consequence of the combined effect of the laser pulse pressure and the ablative nature of the laser process. Surface roughness increases with higher pulse densities as a result of the cumulative effect of greater overlapping between the laser spots during LSP.

\subsection{Residual Stress Distribution}

Residual stress analysis of the surface layer was conducted following the standard hole-drilling straingage method ASTM E837 [21], according to which our maraging steel specimens can be considered as "thick" workpieces since their thickness of $9.5 \mathrm{~mm}$ is well above the minimum required value. According to ASTM E837, the workpiece thickness for a type B rosette should be at least $1.2 D$ or $6.156 \mathrm{~mm}$, where $D$ represents the diameter of the gage circle and is 5.13 $\mathrm{mm}$.

Blind holes were drilled with an RS-200 Milling Guide, while deformations due to relaxation during drilling were detected using CEA-06-062-UM strain gage rosettes by Vishay Measurement Group. The hole-drilling process on all maraging steel specimens was performed to a depth of $1.1 \mathrm{~mm}$ in a stepwise manner with an increment of $0.1 \mathrm{~mm}$. Deformation values were recorded at each increment using LabVIEW. The residual stress distributions were then obtained by processing the deformation data with H-Drill software. Residual stresses were calculated using the integral method with automatic smoothing. In order to determine the effects of LSP on the residual stress state, measurements were carried out on both untreated and LSP treated specimens.

The residual stress measuring point was located on the LSP treated area and approximately $8 \mathrm{~mm}$ from the boundary as shown in Fig. 2.

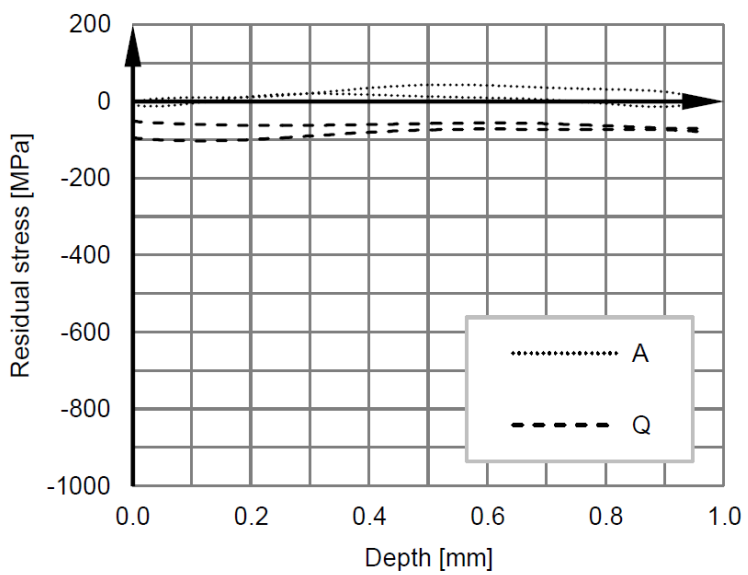

Fig. 5. Residual stress distributions of untreated maraging steel specimens $Q$ and $A$

Charts represented in Figs. 5 to 7 show residual stress profiles in the thin surface layer of the maraging steel specimens, obtained by the hole-drilling straingage method. Each distribution is displayed using two curves, which represent the maximal and minimal 
residual stress component. After LSP treatment, compressive residual stresses are generated in the surface layer because of the mechanical effects of shock waves, which exceed the dynamic yield strength of the maraging steel and cause plastic deformation.

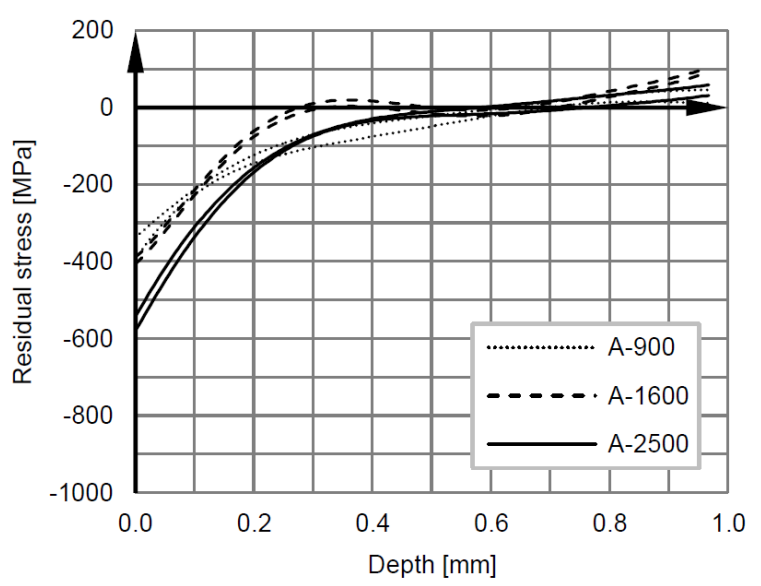

Fig. 6. Residual stress distributions of LSP treated aged maraging steel specimens

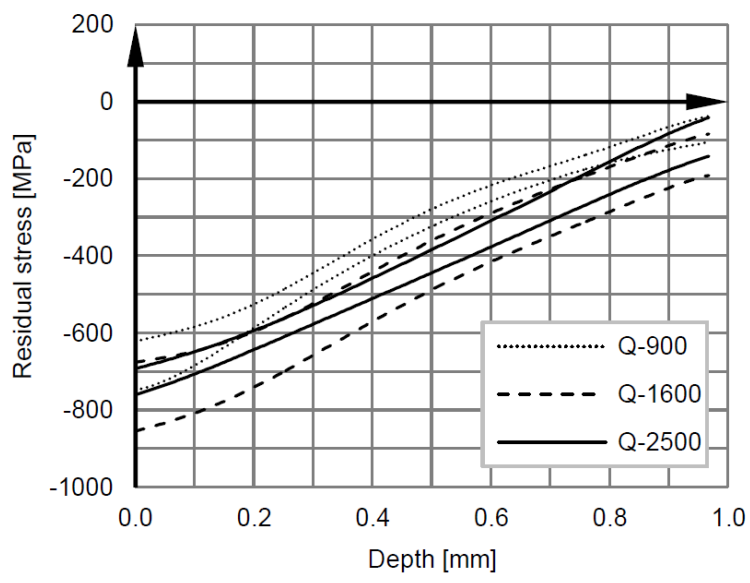

Fig. 7. Residual stress distributions LSP treated quenched maraging steel specimens

As can be observed in Fig. 6, which shows stress distributions after laser peening of aged maraging specimens, compressive stresses reach their maximum at the surface, ranging from $-580 \mathrm{MPa}$ to $-340 \mathrm{MPa}$, while the transition from compressive to tensile state occurs at a depth of approximately $0.7 \mathrm{~mm}$. The lowest compressive stress at the surface was measured on specimen A-900, treated with the lowest pulse density, while the maximum compressive value was noted on specimen A-2500, treated with the highest pulse density.

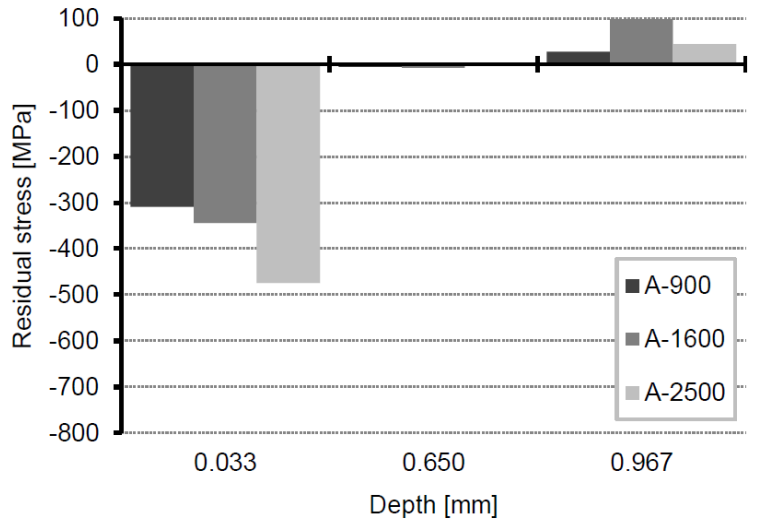

Fig. 8. Residual stresses of LSP treated aged specimens

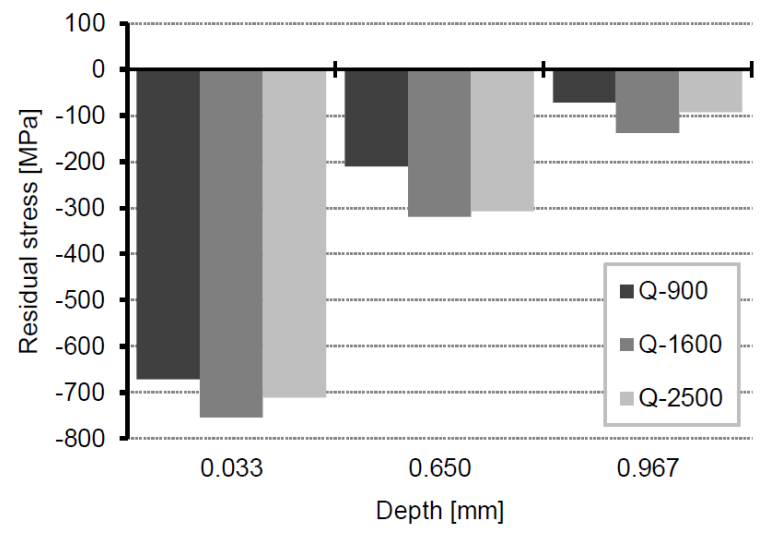

Fig. 9. Residual stresses of $L S P$ treated quenched specimens

LSP generates higher and deeper compressive stresses in quenched maraging steel specimens, as shown in Fig. 7. This phenomenon can be attributed to a greater mechanical effect of shock waves due to the lower yield strength of the quenched condition. After LSP, surface stresses between $-850 \mathrm{MPa}$ and $-620 \mathrm{MPa}$ are detected. The difference in compressive stress generation is evident by comparing the column charts in Figs. 8 and 9. The value of each column was calculated as the average between the maximal and minimal stress component at the corresponding depth. Compressive residual stresses are still present at depth $0.967 \mathrm{~mm}$ in the surface layer of LSP treated quenched specimens. In the case of aged specimens, the transition from compressive to tensile state occurs already at depth $0.650 \mathrm{~mm}$. Average tensile residual stresses at depth $0.967 \mathrm{~mm}$ in the surface layer of aged specimens amount between $30 \mathrm{MPa}$ and $100 \mathrm{MPa}$. The compressive stresses near the surface and indepth increase by using higher LSP pulse density. Higher stresses are a result of the cumulative effect of greater overlapping between the laser spots during LSP. 


\subsection{In-Depth Microhardness Distribution}

The in-depth microhardness distribution was analyzed on specimens Q-2500 and A-2500, which were peened with the highest pulse density and should display more pronounced strain hardening of the surface layer. Microhardness was measured following the standard Vickers test method in accordance with ISO 6507-1:2005 [22]. The location of the in-depth measurement line is shown in Fig. 2. Indentations were carried out using a Vickers indentation unit, applied to a Leitz ORTHOPLAN microscope. The indentation force was performed with a $200 \mathrm{~g}$ load and $15 \mathrm{~s}$ load time. The image of the indentation was then captured through an Olympus ColorView III digital camera, while diagonal lengths were measured with AnalySISdocu software by Olympus Soft Imaging Solutions. Microhardness distribution was obtained with 20 in-depth measurements, where the distance between two separate indentations in the direction perpendicular to the LSP treated surface was $0.1 \mathrm{~mm}$. The average microhardness of unpeened specimens Q and A was $341 \mathrm{HV} 0.2$ and $667 \mathrm{HV} 0.2$, respectively.

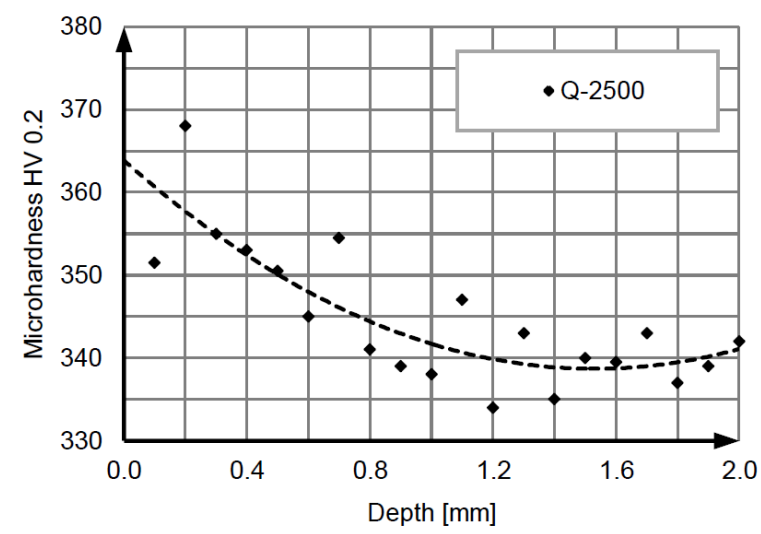

Fig. 10. In-depth microhardness distribution of LSP treated aged specimen Q-2500

In-depth microhardness distributions of the surface layer of laser peened maraging steel specimens Q-2500 and A-2500 are shown in Figs. 10 and 11, respectively. A polynomial trend line of the second order is added to determine if there is any change in the microhardness distribution due to the LSP treatment. As can be observed from the generated regression curves, strain hardening occurs after exposure to the LSP process. Strain hardening, as a consequence of the dislocation density increase due to the mechanical effect of shock waves, is detected as an increase in microhardness. Surface microhardness, determined at the intersection point between the vertical axis and the trend line, is $747 \mathrm{HV} 0.2$ for aged specimen A-2500, and $384 \mathrm{HV} 0.2$ for the quenched specimen Q-2500.

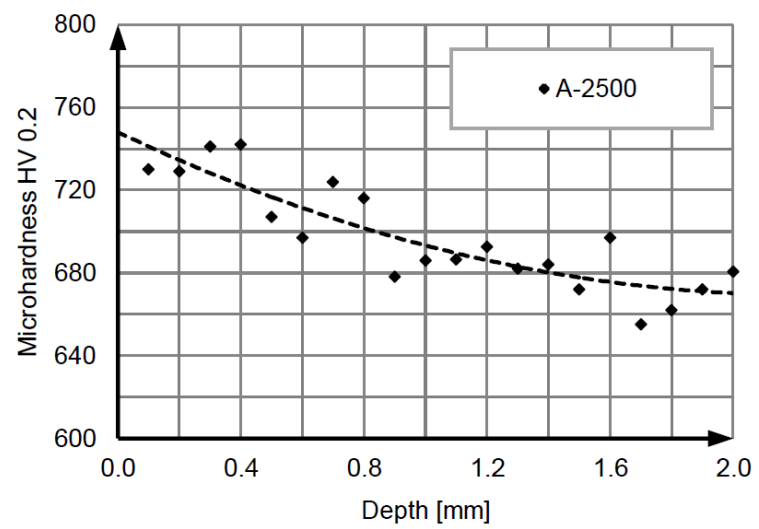

Fig. 11. In-depth microhardness distribution of LSP treated aged specimen A-2500

\section{CONCLUSIONS}

The effects of laser shock peening on the surface integrity characteristics of X2NiCoMo18-9-5 maraging steel were investigated. Specimens, in both quenched and artificially aged condition, were exposed to LSP using different laser pulse densities, while laser pulse energy and duration were constant. The investigated surface integrity characteristics were: surface roughness, in-depth microhardness, and residual stress distribution in the surface layer. In accordance with our research, the following conclusions were established:

- A significant increase in surface roughness, determined with $R a$ and $R z$ measurements, occurs after exposure to LSP. The increase in surface roughness is a consequence of the combined effect of the laser pulse pressure and the ablative nature of the laser process. A comparison between quenched and aged specimens shows similar $R a$ and $R z$ values after LSP treatment.

- After LSP treatment, compressive residual stresses are generated in the maraging steel surface layer due to the mechanical effects of shock waves, which cause plastic deformation. Compressive residual stresses are generated in all LSP treated specimens. LSP generates higher and deeper compressive stresses in quenched maraging steel specimens, ranging between -850 $\mathrm{MPa}$ and $-620 \mathrm{MPa}$. The greater mechanical effect of shock waves is attributed to the lower yield strength of the quenched condition. 
Compressive residual stresses increase by using higher LSP pulse density as a result of the cumulative effect of greater overlapping between the laser spots during LSP.

- LSP causes strain hardening in the maraging steel surface layer, which is detected as an increase in microhardness.

The performed surface integrity analysis shows that a combination of high compressive residual stresses and relatively low surface roughness can be achieved with the appropriate LSP processing parameters. While these surface characteristics may be beneficial for fatigue resistance of $18 \% \mathrm{Ni}$ maraging steel, other influential factors have to be taken into account, such as specimen thickness and the relative distance of edges of the LSP treated area from crack tips. When peening specimens of a few millimeters thick, local tensile residual stresses close to the edges of the LSP irradiated area may occur and have a detrimental effect. In order to confirm a beneficial effect of LSP on mechanical properties of $\mathrm{X} 2 \mathrm{NiCoMo18-9-5}$ maraging steel, fatigue testing should be conducted in future research.

\section{ACKNOWLEDGMENTS}

The authors would like to express their gratitude to the Laser Center of the Polytechnic University of Madrid and its staff for their assistance with the LSP treatment.

\section{REFERENCES}

[1] Rohrbach, K., Schmidt, M. (1990). Maraging steels. Davis, J.R. (ed.), ASM Handbook Volume 1: Properties and Selection: Irons Steels and High Performance Alloys. ASM International, Metals Park, p. 729-800.

[2] Decker, R.F., Floreen, S. (1988). Maraging steel - the first 30 years. Maraging Steels Recent Developments and Applications - Proceedings of Symposium TMS Meeting, p. 1-38.

[3] Cajner, F., Landek, D., Leskovšek V. (2010) Surface modifications of maraging steels used in the manufacture of moulds and dies. Materials and Technology, vol. 44, no. 2, p. 85-91.

[4] Nalla, R.K., Altenberger, I., Noster, U., Liu, G.Y., Scholtes, B., Ritchie R.O. (2003). On the influence of mechanical surface treatments - deep rolling and laser shock peening - on the fatigue behavior of Ti-6Al-4V at ambient and elevated temperatures. Materials Science A, vol. 355, no. 1-2, p. 216230, DOI:10.1016/S0921-5093(03)00069-8.

[5] Trdan, U., Ocaña, J.L., Grum, J. (2011). Surface modification of aluminium alloys with laser shock processing. Strojniški vestnik - Journal of Mechanical Engineering, vol. 57, no. 5, p. 385-393, D0l:10.5545/sv-jme.2010.119.
[6] Bolger, J.A., Montross C.S., Rode, A.V. (1999). Shock waves in basalt rock generated with high-powered lasers in a confined geometry. Journal of Applied Physics, vol. 86, no. 10, p. 54615466, DOI:10.1063/1.371546.

[7] Peyre, P., Fabbro, R., Merrien, P., Lieurade, H.P. (1996). Laser shock processing of aluminium alloys. Application to high cycle fatigue behaviour. Materials Science and Engineering A, vol. 210, no. 1-2, p. 102-113, Dol:10.1016/0921-5093(95)100849.

[8] Zupanc, U., Grum, J. (2011). Surface integrity of shot peened of 7075-T651 aluminium alloy. Strojniški vestnik - Journal of Mechanical Engineering, vol. 57, no. 5, p. 379-384, DOI:10.5545/sv-jme.2010.142.

[9] Schulze, V. (2006). Modern Mechanical Surface Treatment. WILEY-VCH Verlag GmbH \& Co. KGaA, Weinheim.

[10] Žagar, S., Grum, J. (2011). Surface integrity after mechanical hardening of various aluminium alloys. Strojniški vestnik Journal of Mechanical Engineering, vol. 57, no. 4, p. 334-344, D0l:10.5545/sv-jme.2010.092.

[11] Banas, G., Elsayed-Ali, H.E., Lawrence, F.V., Rigsbee, J.M. (1990). Laser shock-induced mechanical and microstructural modification of welded maraging steel. Journal of Applied Physics, vol. 67, no. 5, p. 2380-2384, Dol:10.1063/1.345534.

[12] Grum, J., Zupančič, M., Ocaña, J.L. (2007). Laser shock processing of the maraging steel surface. Materials Science Forum, vol. 537-838, p. 655-662, D0l:10.4028/www. scientific.net/MSF.537-538.655

[13] Grum, J., Zupančič, M., Ocaña, J.L., Morales, M., Porro, J.A. (2008). Laser shock processing as a method of decreasing fatigue of a die-casting die made of maraging steel. International Journal of Microstructure and Materials Properties, vol. 3, no. 2/3, p. 271-281, D0l:10.1504/ IJMMP.2008.018734.

[14] Lavender, C.A., Hong, S.-T., Smith, M.T., Johnson R.T., Lahrman, D. (2008). The effect of laser shock peening on the life and failure mode of a cold pilger die. Journal of Materials Processing Technology, vol. 204, no. 1, p. 486-491, D0I:10.1016/j.jmatprotec.2008.02.002.

[15] Harada, Y., Kobayashi, Y., Nagashima, E., Takeda, H. (2008). Influence of microshot peening on surface characteristics of high-speed tool steel. Proceedings from the $10^{\text {th }}$ ICSP, Tokyo.

[16] Sawada, T., Yanagitani, A. (2010). Properties of cold work tool steel shot peened by $1200 \mathrm{HV}$-class Fe-Cr-B gas atomized powder as shot peening media. Journal of the Japan Institute of Metals, vol. 51, no. 4, p. 735-739, D0l:10.2320/matertrans. MBW200922.

[17] Chang, S.-H., Tang, T.-P., Tai, F.-C. (2011). Enhancement of thermal cracking and mechanical properties of $\mathrm{H} 13$ tool steel by shot peening treatment. Surface Engineering, vol. 27, no. 8, p. 581-586, DOI:10.1179/026708409X12490360425882.

[18] ISO 4287:1997. Geometrical Product Specifications (GPS) - Surface texture: Profile method - Terms, definitions and surface texture parameters. International Organization for Standardization, Geneva.

[19] DIN 4768:1990-05: Determination of values of surface roughness parameters $R a, R z, R$ max using electrical contact (stylus) instruments; concepts and measuring conditions. German Institute for Standardization, Berlin. 
[20] Amaral, M.M., Raele, M.P., Caly, J.P., Samad, R.E., Vieira Jr, N.D., Freitas, A.Z. (2009). Roughness measurement methodology according to DIN 4768 using optical coherence tomography (OCT). SPIE Proceedings - Modeling Aspects in Optical Metrology II, vol. 7390, Bellingham, Dol:10.1117/12.827748.
[21] ASTM E837. Standard Test Method for Determining Residual Stresses by the Hole-Drilling Strain-Gage Method. ASTM International, West Conshohocken.

[22] ISO 6507-1:2005. Metallic materials - Vickers hardness test - Part 1: Test method. International Organization for Standardization, Geneva. 